\section{Theory of mind in schizophrenia}

\author{
Meta-analysis
} MIRJAM SPRONG, PATRICIA SCHOTHORST, ELLEN VOS, JOOP HOX
and HERMAN VAN ENGELAND

\author{
Background Mentalising impairment \\ (an impaired ability to think about people \\ in terms of their mental states) has \\ frequently been associated with \\ schizophrenia.
}

Aims To assess the magnitude of the deficit and analyse associated factors.

Method Twenty-nine studies of mentalising in schizophrenia (combined $n=1518$ ), published between January 1993 and May 2006, were included to estimate overall effect size. Study descriptors predicted to influence effect size were analysed using weighted regressionanalysis techniques. Separate analyses were performed for symptom subgroups and task types.

Results The estimated overall effect size was large and statistically significant $(d=-1.255, P<0.0001)$ and was not significantly affected by sample characteristics. All symptom subgroups showed significant mentalising impairment, but participants with symptoms of disorganisation were significantly more impaired than the other subgroups $(P<0.01)$.

\section{Conclusions This meta-analysis showed significant and stable mentalising impairment in schizophrenia. The finding that patients in remission are also impaired favours the notion that mentalising impairment represents a possible trait marker of schizophrenia.}

Declaration of interest None. Funding detailed in Acknowledgements
'Theory of mind' and 'mentalising' refer to the cognitive ability to attribute mental states such as thoughts, beliefs and intentions to people, allowing an individual to explain, manipulate and predict behaviour. In 1992 Frith proposed a relationship between theory of mind and schizophrenia, and argued that several symptoms of schizophrenia could be explained by mentalising impairment (Frith, 1992). This led to a substantial body of research which has recently been critically reviewed twice (Brüne, 2005a; Harrington et al, 2005a). In both reviews it was concluded that theory of mind is impaired in individuals with schizophrenia. Although these reviews were executed thoroughly, they are limited to a qualitative description of the observed deficit, thus lacking important information on the magnitude of the effect. The purpose of this meta-analysis is to produce a synthesised effect size estimate that has considerably more power than the individual studies. In addition, effects of study characteristics on the findings are analysed.

\section{METHOD}

\section{Study selection}

An extensive literature search was conducted in the electronic databases Medline, EMBASE and PsycINFO (January 1993 to May 2006) using the following key words: theory of mind, mentalizing, social cognition, schizophrenia, and psychosis. Additional studies were identified by checking the reference lists from identified reviews and papers on the topic. To ensure that we did not overlook studies published by May 2006 but not included in the computerised databases by that date, a journalby-journal search was performed in the January 2006 to May 2006 editions of the American Journal of Psychiatry, Biological Psychiatry, Journal of Nervous and Mental Disease, Psychiatry Research, Schizophrenia Bulletin, Schizophrenia Research and Psychological Medicine. Studies considered eligible for this meta-analysis were empirical research studies written in the English language and published in peerreviewed journals. Research samples had to be composed of adults diagnosed with schizophrenia or schizoaffective disorder according to the established diagnostic systems (DSM or ICD). Their sample group's mentalising performance had to be compared with that of healthy controls. Measures of mentalising included in this metaanalysis are described below. Finally, sufficient data had to be reported for the computation of the standardised mean difference (Lipsey \& Wilson, 2001).

\section{Types of mentalising tasks}

There is a fair amount of agreement on the definition of theory of mind among researchers. However, this definition is broad, perhaps reflecting the fact that it is probably not a unitary function. This has led to a wide variation in the operationalisation of the concept. One of the most frequently used types of mentalising tasks is the false belief or deception task (e.g. Frith \& Corcoran, 1996; Corcoran et al, 1997; Doody et al, 1998; Mazza et al, 2001). In a first-order false belief/deception task, the ability to understand that someone can hold a belief that is different from the actual state of affairs is assessed. In a second-order false belief/deception task, participants have to infer the (false) beliefs of one character about the (false) beliefs of a second character.

A second type of theory of mind task commonly used in schizophrenia research is an intention-inferencing task, in which the ability to infer a character's intentions from information in a short story is assessed (e.g. Sarfati et al, 1997a,b, 1999, 2000; Sarfati \& Hardy-Baylé, 1999). A third type of task measures the ability to understand indirect speech, such as in irony, banter, hints and metaphors (e.g. Corcoran et al, 1995; Langdon et al, 2002; Corcoran, 2003; Corcoran \& Frith, 2003; Craig et al, 2004). This is based on the notion that for the understanding of indirect speech an understanding of another person's mental state is required (e.g. Sperber \& Wilson, 2002). However, Langdon \& Coltheart (2004) showed that comprehension of irony and comprehension of metaphors are unrelated and that having an intact theory of mind is a prerequisite for the interpretation of irony but not for 
the interpretation of metaphors. Therefore, data on the interpretation of metaphors were excluded from this meta-analysis.

A fourth, less commonly used type of theory of mind task in schizophrenia research is the attribution of mental states to animated geometric shapes which interact in a 'socially' complex way (Blakemore et al, 2003; Russell et al, 2006). This type of task may not be fully comparable with the other theory of mind tasks because of the higher level of abstraction involved. Finally, in some studies the 'eyes' task is used, in which participants have to infer mental states from looking at pictures of eyes (Kington et al, 2000; Russell et al, 2000; Kelemen et al, 2005). This has been referred to as a theory of mind task, but at face value the construct being measured seems to be different from that assessed by the other paradigms, perhaps assessing emotion recognition abilities or empathy rather than theory of mind.

Since there is a serious lack of research on the psychometric properties (including construct validity and criterion validity) of the many different theory of mind tasks that have been developed (Harrington et $a l, 2005 a$ ), it may not be possible to formulate completely objective inclusion criteria regarding the type of tasks used in the studies. In this meta-analysis this problem is addressed statistically in two ways. First, homogeneity analyses are used to check whether the grouping of effect sizes from different studies shows more variation than would be expected from sampling error alone, indicating that the effect sizes may not be comparable. A second approach to this problem is to break down the overall mean effect size into mean effect sizes for different types of tasks. For these mean effect sizes per type of task to be meaningful, we (subjectively) set a minimum of five eligible studies per sub-task analysis. This led to the exclusion of two studies using tasks assessing the attribution of mental states to abstract shapes rather than humans (Blakemore et al, 2003; Russell et al, 2006), and three studies in which the 'eyes' task was used (Kington et al, 2000; Russell et al, 2000; Kelemen et al, 2005).

\section{Schizophrenia subgrouping}

Ever since Frith's first proposal (Frith, 1992), the association between mentalising and the core symptoms of schizophrenia has been an important focus of research interest. Schizophrenia is a heterogeneous disorder and various subgrouping methods have been used, based on different theories regarding the relationship between mentalising and symptomatology.

In earlier studies, Frith and colleagues divided their schizophrenia samples into six symptom subgroups (Corcoran et al, 1995). In their later studies, the number of subgroups was reduced to four, categorised as follows:

(a) behavioural signs of negative symptoms and/or incoherence;

(b) paranoid symptoms (delusions of persecution, delusions of reference, and thirdperson hallucinations);

(c) passivity experiences (delusions of control, thought insertion, and thought broadcasting);

(d) symptoms in remission.

The first group was predicted to be the most impaired, because of these patients' incapacity to represent the mental states of others as well as themselves. Paranoid patients would perform poorly because of their difficulties in monitoring other people's intentions. Patients whose symptoms were in remission and patients with passivity symptoms were predicted to have normal mentalizing abilities. These hypotheses were largely confirmed and have repeatedly been replicated (Frith \& Corcoran, 1996; Corcoran et al, 1997; Pickup \& Frith, 2001).

Sarfati and colleagues (Sarfati et al, 1997a,b, 1999; Sarfati \& Hardy-Baylé, 1999) and Zalla et al (2006) suggested that impairment of theory of mind is related to thought disorder, reflecting an executive functioning deficit. Thus, their samples were divided into those with and those without thought disorder. In all of their studies thought-disordered participants performed significantly more poorly than healthy controls. However, in two of the studies the non-disorganised participants also showed poor performance (Sarfati et al, 1997b; Zalla et al, 2006).

Three research groups studied the relationship between mentalising and paranoid delusions (Randall et al, 2003; Craig et al, 2004; Harrington et al, 2005b). In all three studies patients with paranoid delusions showed impairment of theory of mind relative to the normal control group. However, in the study by Randall et al (2003), theory of mind performances of the paranoid and non-paranoid subgroups did not differ significantly from each other.
Lastly, Herold et al (2002) investigated whether the deficit in theory of mind was state- or trait-dependent and therefore assessed patients whose schizophrenia was in remission. Results showed that theory of mind impairment was still present in the remission phase of the illness.

\section{Moderator variables}

Published research suggests a number of variables that may affect mentalising performance and thus influence effect size. Hence, we aimed to code these variables in order to evaluate their influence on the effect size. Potential moderator variables at individual patient level are age, gender, medication, IQ, disease status (acute, chronic or in remission), severity of psychopathology, and symptoms. To analyse the effect of specific clusters of symptoms on mentalising impairment, the symptom subgroups used by different research groups were divided into four categories:

(a) symptoms of disorganisation;

(b) no symptoms of disorganisation;

(c) paranoid symptoms;

(d) remitted patients.

The disorganised subgroup was composed of the behavioural symptoms subgroup of the studies by Frith and colleagues (Corcoran et al, 1995, 1997; Pickup \& Frith, 2001) and the disorganised subgroups of the Sarfati, Mazza and Zalla studies (Sarfati et al, 1997a,b, 1999; Sarfati \& Hardy-Baylé, 1999; Mazza et al, 2001; Zalla et al, 2006). The non-disorganised patients of the Sarfati and Zalla studies were combined into the second subgroup (Sarfati et al, 1997a,b, 1999; Sarfati \& Hardy-Baylé, 1999; Zalla et al, 2006). For the paranoid subgroup the results of the studies focusing on paranoid schizophrenia (Randall et al, 2003; Craig et al, 2004; Harrington et al, 2005b) were combined with the results for the paranoid subgroups of the studies by Frith and colleagues (Corcoran et al, 1995, 1997; Pickup \& Frith, 2001). The remitted disease subgroup comprised the patients in remission in the studies by Herold et al (2002), Randall et al (2003) and Frith and colleagues (Corcoran et al, 1995; Corcoran et al, 1997; Pickup \& Frith, 2001). The passivity subgroup of Frith and colleagues was not coded, because results for that subgroup were reported only in two studies.

Potential moderators at study level are the matching of patients and controls on 
group characteristics (e.g. mean age, mean IQ, gender distribution), type of mentalising task used, and whether the task is administered verbally or non-verbally. Four types of theory of mind tasks were distinguished: first-order false belief/deception; second-order false belief/deception; intention inferencing; and comprehension of indirect speech. Some tasks did not fit in any of these categories, for example the false belief/deception tasks for which the orders were unknown or mixed.

Within the different task paradigms there is also variation in whether tasks are presented in a verbal or non-verbal form. It has been suggested that verbalisation may be impoverished in schizophrenia and may constitute an experimental bias in favour of a theory of mind deficit in people with schizophrenia (e.g. Sarfati et al, 1999). In a separate coding, tasks were classified as verbal or non-verbal.

\section{Coding}

Each study was coded independently by two authors (M.S. and E.V.). In case of discrepancies, consensus was reached in conference with the whole research group. When results were reported in graphical form only an email was sent to the author with a request for the exact numerical results.

\section{Data collection and analysis}

For each study an unbiased standardised mean difference $(d)$, was calculated using reported means and standard deviations. This effect size statistic is computed as the difference between the mean of the schizophrenia group and the mean of the control group, divided by the pooled standard deviation. Hedges' formula was applied to correct for upwardly biased estimation of the effect size in small samples (Lipsey $\&$ Wilson, 2001).

When means and standard deviations were not available, $d$ was calculated from the reported $t$ or $F$ values. In cases where the only reported outcome variable was the proportion of participants with a good (or poor) performance, $d$ was estimated using the probit transformation method (Lipsey \& Wilson, 2001). A sensitivity analysis was performed to check whether there was any significant effect of using probittransformed effect sizes on the overall effect size. In studies in which data were reported for (symptom) subgroups only, data were first pooled and then compared as one group with the control group. In addition, the effect sizes of symptom subgroups were calculated for subsequent analyses. Several studies used more than one (sub)task to assess theory of mind, and therefore had more than one effect size; in these cases a pooled effect size was computed. However, if the authors had included a composite score, the effect size of this score was calculated. Again, effect sizes for different task types were calculated for subsequent analyses. In addition to the individual effect sizes and $95 \%$ confidence intervals, $P$ values were calculated for each study using two-tailed independent $t$-tests and $\chi^{2}$-tests.

The mean effect size across studies was calculated by weighting each effect size by the inverse of its sampling variance. A confidence interval and $z$-value were calculated to examine the statistical significance of the effect. To test whether the individual effect sizes are good estimators of the population effect size, the homogeneity statistic $Q$ was calculated (Lipsey \& Wilson, 2001). Because sample sizes are small in the subgroup and task type analyses (see below), a random effects model was fitted to the data (Lipsey $\&$ Wilson, 2001). To examine publication bias, a fail-safe number was computed using Orwin's formula (Lipsey \& Wilson, 2001). This indicates the number of studies with null effects that have to reside in file drawers to reduce the mean effect size to a negligible level (which we set at 0.2). Weighted regression analysis was performed using the statistical package MetaStat (Rudner et al, 2002) to evaluate whether group differences in IQ, gender and age had an impact on effect size. Other variables with a potential influence on effect size, such as patient status, medication use and severity of psychopathology, could not be analysed because of the small number of studies reporting results for these parameters. Separate analyses were performed to analyse whether mentalising impairment is different for different symptom subgroups or for different types of mentalising tasks.

\section{RESULTS}

The literature search resulted in a total of 32 studies meeting the inclusion criteria. One publication (Langdon et al, 2002a) was excluded because data concerning the same participants had been reported in another paper (Langdon et al, 2002b).
Sample characteristics ( $n$, mean age, percentage of males, mean score on the Binois-Pichot Vocabulary Scale and mean score on the non-verbal theory of mind test) were exactly the same in two studies by Sarfati and colleagues (Sarfati \& Hardy-Baylé, 1999; Sarfati et al, 2000), suggesting that the same patient samples had been used. Because in the first of these studies the patient sample was divided into symptom subgroups, but more control participants and an additional theory of mind task were used in the latter study, instead of selecting one of the two studies the results of both were combined. Because we were unable to contact the authors of one study within the time frame of data collection and data analysis to obtain the exact numerical results which were not reported in the article, the results of that study could not be included in the meta-analysis (Frith \& Corcoran, 1996). The characteristics of the remaining 29 studies with a total of 831 patients (mean age 35.9 years, $70 \%$ male, mean IQ 98.7) and 687 controls (mean age 35.2 years, $60 \%$ male, mean IQ 105.3) are listed in Table 1.

\section{Analysis of the total sample}

Figure 1 shows the 29 individual effect sizes with their $95 \%$ confidence intervals. None of the confidence intervals includes the value zero, indicating a statistically significant effect for each study. The weighted mean effect size of the combined sample is $-1.255(95 \%$ CI -1.441 to -1.069$)$ which is also statistically significant $(z=13.25, P<0.0001)$. Homogeneity analysis showed that there was homogeneity among studies $(Q=29.13$, d.f. $=28$, $P<0.41$ ), and weighted regression analysis did not show any relationship between effect size and difference between patient and control groups in IQ $(P=0.193)$, proportion of males $(P=0.115)$ and age $(P=0.147)$. The fail-safe number was 153 , which indicates that 153 unpublished studies are required to reduce the effect size of the combined findings to a negligible level.

\section{Analyses of the symptom subgroups}

Mean effect sizes and confidence intervals of the symptom subgroups are displayed in Fig. 2. The disorganised patients performed worst on the mentalising tasks compared with healthy controls ( $d=-2.231,95 \%$ CI -2.565 to -1.897 , 
Table I Summary of studies included in the meta-analysis

\begin{tabular}{|c|c|c|c|c|c|c|c|}
\hline \multirow[t]{2}{*}{ Study } & \multicolumn{4}{|c|}{ Schizophrenia/control sample } & \multirow[t]{2}{*}{ Schizophrenia subgroups } & \multirow[t]{2}{*}{ Mentalising tasks } & \multirow[t]{2}{*}{$P^{2}$} \\
\hline & $n$ & $\begin{array}{l}\text { Mean age } \\
\text { (years) }\end{array}$ & $\begin{array}{c}\text { Males } \\
(\%)\end{array}$ & $\begin{array}{l}\text { Mean } \\
\mathrm{IQ}^{\prime}\end{array}$ & & & \\
\hline Corcoran et al (1995) & $55 / 30$ & $32 / 31$ & $69 / 67$ & $98 / 107$ & $\begin{array}{l}\text { Negative, incoherent, paranoid, } \\
\text { passivity, other, remission }\end{array}$ & Hinting task; 10 verbal stories & $<0.0005$ \\
\hline Sarfati et al (1997a) & $24 / 24$ & $32 / 32$ & $79 / 58$ & NR & With and without disorganisation & Intention-inferencing; 28 picture stories & $<0.0005$ \\
\hline Sarfati et al (1997b) & $12 / 12$ & $27 / 26$ & $42 / 50$ & NR & No subgroups & $\begin{array}{l}\text { False belief task; } 15 \text { picture stories } \\
\text { Intention-inferencing; } 15 \text { picture stories }\end{array}$ & $\begin{array}{l}<0.0005 \\
<0.005\end{array}$ \\
\hline Corcoran et al (1997) & $44 / 40$ & $30 / 32$ & $71 / 43$ & $102 / 108$ & $\begin{array}{l}\text { Behavioural, paranoid, passivity, } \\
\text { remission }\end{array}$ & $\begin{array}{l}\text { First-order false belief; } 10 \text { verbal/picture } \\
\text { stories }\end{array}$ & $<0.0005$ \\
\hline Langdon et al (1997) & $20 / 20$ & $33 / N R$ & $45 / N R$ & NR & No subgroups & $\begin{array}{l}\text { Pretence; } 3 \text { picture stories } \\
\text { Unrealised goal; } 3 \text { picture stories } \\
\text { Intention-inferencing; } 3 \text { picture stories } \\
\text { First-order false belief; } 3 \text { picture stories }\end{array}$ & $\begin{array}{l}<0.025 \\
<0.05 \\
<0.05 \\
<0.0005\end{array}$ \\
\hline Doody et al (1998) & $28 / 20$ & $46 / 20$ & $61 / 45$ & $108 / 109$ & No subgroups & $\begin{array}{l}\text { First-order false belief; I verbal story } \\
\text { Second-order false belief; I verbal story }\end{array}$ & $\begin{aligned} & 0.5 \\
< & 0.005\end{aligned}$ \\
\hline Sarfati et al (1999) & $26 / 13$ & $32 / 33$ & $81 / 85$ & NR & With and without disorganisation & $\begin{array}{l}\text { Intention-inferencing; } 28 \text { picture stories } \\
\text { Intention-inferencing; } 28 \text { verbal stories }\end{array}$ & $\begin{array}{l}<0.0005 \\
<0.0005\end{array}$ \\
\hline $\begin{array}{l}\text { Sarfati \& Hardy-Baylé } \\
\text { (1999), combined with } \\
\text { Sarfati et al (2000) }\end{array}$ & $25 / 25$ & $33 / N R$ & $28 / N R$ & NR & With and without disorganisation & Intention-inferencing; I4 picture stories & $<0.0005$ \\
\hline Mazza et al (200I) & $35 / 17$ & $34 / 37$ & $89 / 86$ & $88 / 90$ & No subgroups & $\begin{array}{l}\text { First-order false belief; } 2 \text { verbal stories } \\
\text { Second-order false belief; } 2 \text { verbal stories }\end{array}$ & $\begin{array}{l}<0.0005 \\
<0.00005\end{array}$ \\
\hline Pickup \& Frith (200I) & $40 / 35$ & $39 / 43$ & $73 / 54$ & $93 / 103$ & $\begin{array}{l}\text { Behavioural, paranoid, passivity, } \\
\text { remission }\end{array}$ & $\begin{array}{l}\text { First-order false belief; } 2 \text { verbal stories } \\
\text { Second-order false belief; } 2 \text { verbal stories }\end{array}$ & $\begin{aligned} & 0.5 \\
< & 0.005\end{aligned}$ \\
\hline $\begin{array}{l}\text { Langdon \& Coltheart } \\
\text { (200I) }\end{array}$ & $32 / 24$ & $37 / 35$ & $56 / 50$ & NR & No subgroups & False belief; 4 picture stories & $<0.0005$ \\
\hline Langdon et al (2002b) & $25 / 20$ & NR & NR & NR & No subgroups & $\begin{array}{l}\text { False belief; } 4 \text { picture stories } \\
\text { Hinting task; } 10 \text { verbal stories }\end{array}$ & $\begin{array}{l}<0.0005 \\
<0.0005\end{array}$ \\
\hline Herold et al (2002) & $20 / 20$ & NR & NR & NR & Paranoid in remission & $\begin{array}{l}\text { First-order false belief; I verbal story } \\
\text { Second-order false belief; I verbal story } \\
\text { Irony task; } 2 \text { verbal stories }\end{array}$ & $\begin{array}{l}>0.05 \\
>0.05 \\
<0.005\end{array}$ \\
\hline Janssen et al (2003) & $43 / 43$ & $32 / 35$ & $56 / 51$ & $105 / 113$ & No subgroups & $\begin{array}{l}\text { First-order false belief; } 2 \text { verbal stories } \\
\text { Hinting task; } 10 \text { verbal stories }\end{array}$ & $\begin{array}{l}>0.05 \\
<0.005\end{array}$ \\
\hline $\begin{array}{l}\text { Corcoran \& Frith } \\
\text { (2003) }\end{array}$ & $59 / 44$ & $4 I / 40$ & $85 / 80$ & $101 / 103$ & No subgroups & $\begin{array}{l}\text { Hinting task; } 10 \text { verbal stories } \\
\text { False belief; } 4 \text { verbal/picture stories }\end{array}$ & $\begin{array}{l}<0.0005 \\
<0.0005\end{array}$ \\
\hline Brunet et al (2003a) & $7 / 8$ & $31 / 23$ & $100 / 100$ & $111 / 119$ & No subgroups & Intention-inferencing; 18 picture stories & $<0.025$ \\
\hline Brunet et al (2003b) & $25 / 25$ & $31 / 34$ & $76 / 68$ & NR & No subgroups & Intention-inferencing; I4 picture stories & $<0.005$ \\
\hline Mazza et al (2003) & $39 / 20$ & $43 / 43$ & $83 / 65$ & $87 / 86$ & Positive and negative & $\begin{array}{l}\text { First-order false belief; } 2 \text { verbal stories } \\
\text { Second-order false belief; } 2 \text { verbal stories }\end{array}$ & $\begin{array}{l}<0.0005 \\
<0.0005\end{array}$ \\
\hline Brüne (2003) & $23 / 12$ & $29 / 30$ & $74 / 58$ & $92 / 107$ & No subgroups & $\begin{array}{l}\text { First-order false belief; I picture story } \\
\text { Second-order false belief; I picture story } \\
\text { False belief; I picture story }\end{array}$ & $\begin{array}{l}>0.05 \\
<0.05 \\
>0.05\end{array}$ \\
\hline Corcoran (2003) & $39 / 44$ & $41 / 40$ & $82 / 80$ & $103 / 104$ & No subgroups & Hinting; 10 verbal stories & $<0.005$ \\
\hline Randall et al (2003) & $32 / 18$ & $35 / 32$ & $69 / 61$ & $110 / 115$ & Paranoid and paranoid in remission & $\begin{array}{l}\text { First-order false belief; } 3 \text { verbal stories } \\
\text { Second-order false belief; } 3 \text { verbal stories }\end{array}$ & $\begin{array}{l}<0.0005 \\
<0.0005\end{array}$ \\
\hline Craig et al (2004) & $16 / 16$ & $32 / 29$ & $69 / 69$ & $105 / 110$ & Paranoid only & Hinting; 10 verbal stories & $<0.0005$ \\
\hline Marjoram et al (2005a) & $20 / 20$ & $40 / 40$ & $60 / 55$ & $97 / 100$ & No subgroups & False belief; 31 verbal/picture stories & $<0.005$ \\
\hline Marjoram et al (2005b) & $15 / 15$ & $28 / 34$ & $87 / 67$ & $97 / 106$ & No subgroups & Hinting; 10 verbal stories & $<0.0005$ \\
\hline
\end{tabular}




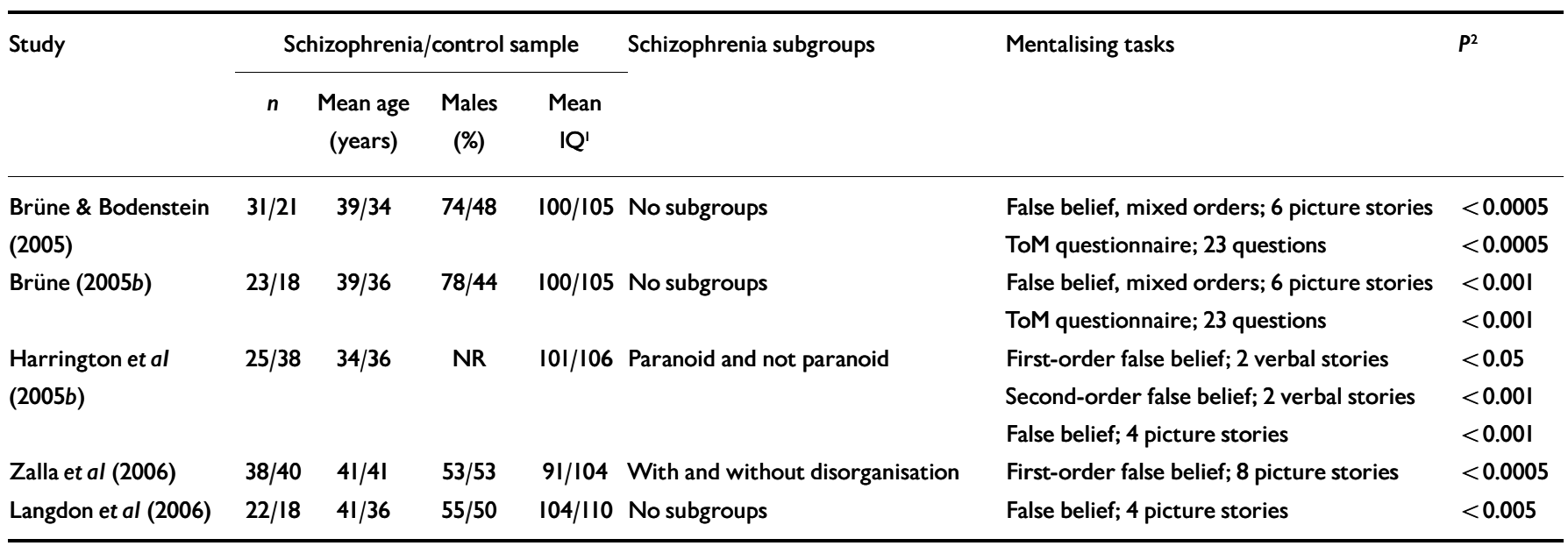

NR, not reported; ToM, theory of mind.

I. Wechsler Adult Intelligence Scale.

2. Significance level of the difference in performance between the patients and the controls.

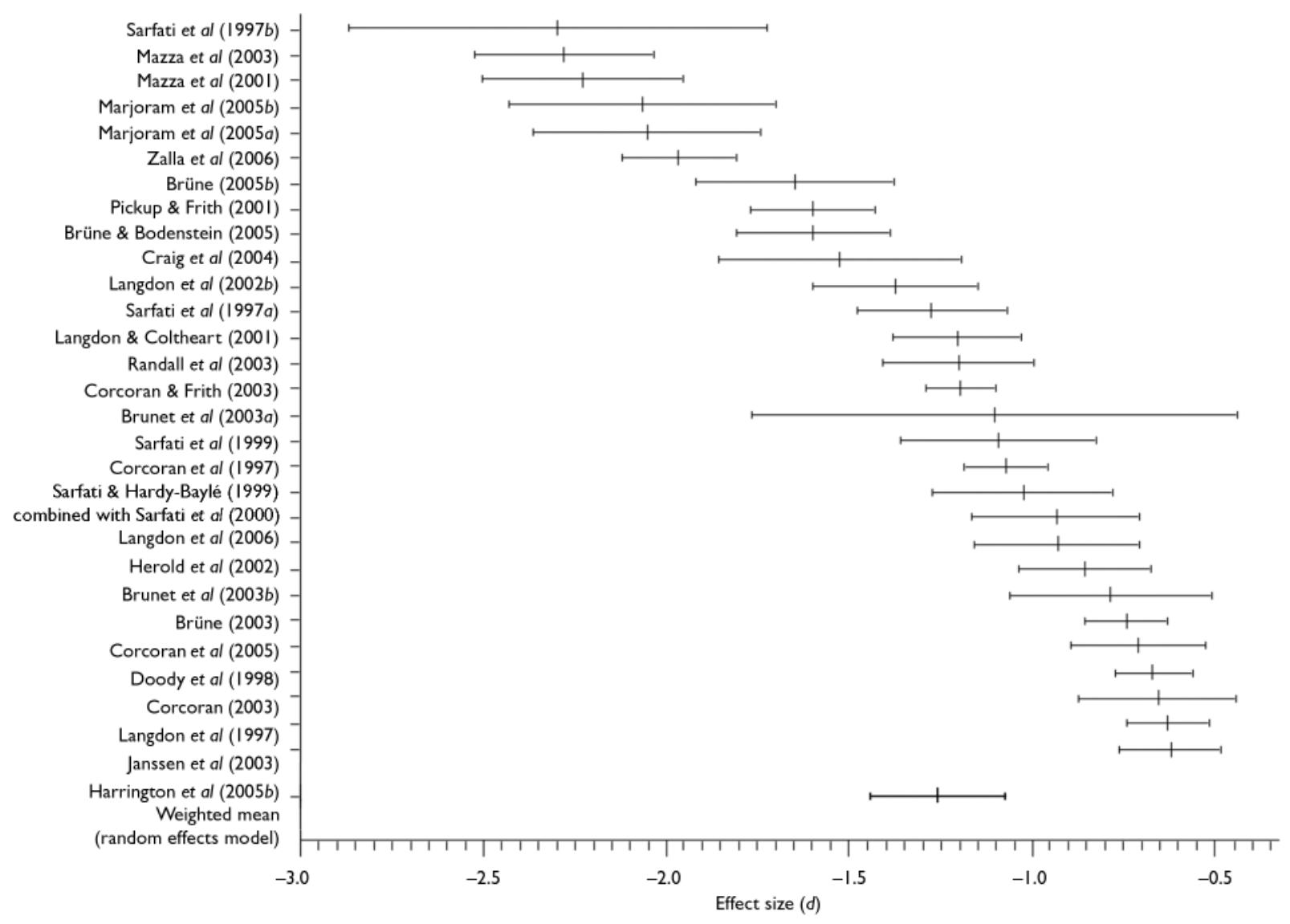

Fig. I Individual and mean effect sizes $(d)$ and $95 \%$ confidence intervals of mentalising deficits in schizophrenia.

$P<0.01)$. The confidence interval of the mean effect size in the disorganized subgroup shows no overlap with that in the non-disorganised $(d=-1.278,95 \%$ CI -1.771 to $-0.785, P<0.01)$ and paranoid subgroups $(d=-1.241,95 \% \mathrm{CI}-1.514$ to $-0.968, P<0.01)$, indicating that the difference between the disorganised subgroup and the other subgroups is statistically significant. This was confirmed by post hoc comparisons of the mean effect size of the disorganised subgroup $v$. the mean effect sizes of the other three symptom subgroups (all $P$ values $<0.01$ ). Interestingly, patients in remission also showed a significantly worse performance than controls ( $d=<0.692,95 \%$ CI -1.017 to -0.367 , $P<0.01)$. The homogeneity statistic of the non-disorganised subgroup was statistically significant $(Q=7.3816$, d.f. $=4, P<0.05)$, indicating that the effect sizes within this 


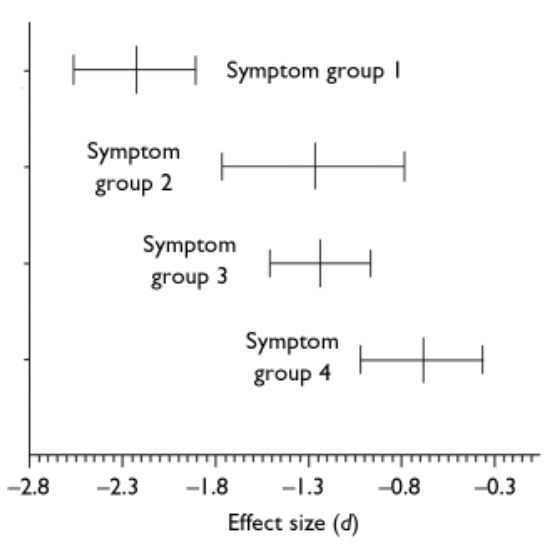

Fig. 2 Mean effect sizes ( $d$ ) and $95 \%$ confidence intervals of mentalising deficits in symptom subgroups of schizophrenia: group I, with disorganisation ( $n=9)$; group 2 , without disorganisation $(n=5)$; group 3 , paranoid $(n=6)$; group 4, remission $(n=5)$.

subgroup analysis differed more than would be expected from sampling error alone, perhaps owing to differences associated with study (or sample) characteristics. This was somewhat surprising, since four of the five studies were by the same research group. The finding that the other three homogeneity statistics were not statistically significant suggests that although different authors might have used different criteria for their symptom subgroups, combining these subgroups was meaningful.

\section{Analyses of the types of mentalising tasks}

The mean effect sizes and confidence intervals of the four theory of mind task categories are shown in Fig. 3. The mean effect sizes of the first-order tasks $(d=-1.193,95 \%$ CI -1.666 to -0.720 , $P<0.01)$ and the second-order tasks ( $d=-1.443,95 \%$ CI -1.867 to -1.019 , $P<0.01)$ have homogeneity statistics indicating heterogeneity among the effect sizes: $Q=97.691, \quad$ d.f. $=12 \quad(P<0.01) \quad$ and $Q=17.875$, d.f. $=6(P<0.01)$ respectively. In contrast, the mean effect sizes within both the indirect speech tasks $(d=<1.040$, $95 \%$ CI -1.301 to $-0.779, P<0.01$ ) and the intention-inferencing tasks $(d=-0.959,95 \%$ CI -1.228 to -0.690 , $P<0.01)$ are both homogeneous. The difference between the mean effect sizes for different subtasks could not be analysed statistically, because not all effect sizes were statistically independent since in one study different types of tasks might have been used.

The mean effect size of studies using verbal tasks is comparable with the mean effect size of studies using non-verbal tasks (verbal, $d=-1.221,95 \% \mathrm{CI}-1.462$ to -0.980 ; non-verbal $d=-1.251,95 \%$ CI -1.496 to -1.006$)$. The homogeneity statistics of the verbal and non-verbal tasks both show heterogeneity among the effect sizes. Again, the difference could not be analysed because of statistical dependence.

\section{DISCUSSION}

The aim of this meta-analysis was to investigate the extent of mentalising impairment in people with schizophrenia. By combining 29 studies, a total sample size was created of over 1500 participants. The overall effect size was -1.1255 , indicating that on average the theory of mind performance of participants with schizophrenia is more than one standard deviation below that of healthy controls. According to a widely used convention for appraising the magnitude of effect sizes this is considered a large effect (Cohen, 1988). Homogeneity analysis showed that the mean effect size of the combined samples is a good estimate of the typical effect size in the population. The large fail-safe number makes the 'file drawer' problem, which is a limitation of some meta-analyses, negligible.

The moderator variables IQ, gender and age did not significantly affect mean effect size. Thus, the impairment in theory of mind is robust and is not readily moderated by variables that may seem relevant. However, the effect of other potentially important moderator variables such as medication use and duration and severity of illness could not be analysed owing to a lack of information on these characteristics in many studies.

Participants with schizophrenia who had signs and symptoms of disorganisation were found to be significantly more impaired in terms of theory of mind than those in the other symptom subgroups. However, these results may also be explained by the composition of the disorganised symptom subgroup. The behavioural subgroup of the studies by Frith and colleagues was ranked highest in their hierarchical model. Thus, individuals in this group might also have had symptoms of the paranoid and/or passivity subgroup. This brings the risk that poorer performance in this

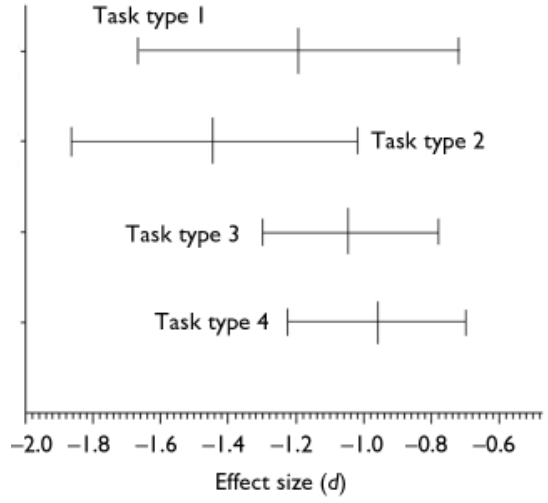

Fig. 3 Mean effect sizes (d) and $95 \%$ confidence intervals of mentalising deficits for different types of mentalising tasks: I, first-order false belief and deception tasks ( $n=13$ ); 2 , second-order false belief and deception tasks $(n=7) ; 3$, tasks assessing the comprehension of indirect speech $(n=8) ; 4$, intention-inferencing tasks $(n=7)$.

group may be explained by having more severe and complex symptoms (Harrington et al, 2005a). Similarly, in two of the four studies by Sarfati and colleagues the disorganised subgroup had more general psychopathology, which might explain their poorer theory of mind performance (Sarfati \& Hardy-Baylé, 1999; Sarfati et al, 1999).

The mean effect size $(d=-0.692)$ of mentalising impairment in patients in remission was smaller than in the other symptom subgroups, but is still considered to be medium to large (Cohen, 1988). Moreover, this effect did not differ significantly from the effect sizes of the disorganised and paranoid subgroups.

Unexpectedly - and despite apparent differences in type and difficulty of the theory of mind tasks - the mean effect sizes for different task types were found to be similar. An explanation might be that our method of grouping studies by task types was not correct. This is supported by the finding that two of the four task type analyses showed heterogeneity among effect sizes. However, since there is a lack of research on the psychometric properties of the tasks that were used, such as construct and concurrent validity, it is not yet possible to categorise these tasks objectively.

There was also no difference between the mean effect sizes of verbal and nonverbal tasks, which is consistent with the findings of Sarfati and colleagues (Sarfati et al, 1999, 2000). Thus, impairment of theory of mind does not to appear to be 
affected by verbalisation deficits that have been reported in people with schizophrenia.

\section{Mentalising in schizophrenia: generalised v. specific impairment}

As shown by Heinrichs \& Zakzanis (1998), people with schizophrenia show generalised neurocognitive impairment. On their list of 22 mean effect sizes of common neurocognitive tests, the effect size of mentalising impairment would be ranked fourth. An interesting question is whether poor mentalising performance in schizophrenia interacts with or is influenced by general cognitive impairment. This problem is acknowledged by some authors, who corrected for general cognitive abilities by matching groups on IQ, covarying out cognitive variables (e.g. attention, executive functioning, memory, general picture sequencing abilities) or excluding participants from statistical analyses if they answered reality questions about the theory of mind stories incorrectly. In their reviews, Brüne (2005a: p. 25, Table 1) and Harrington et al (2005a: pp. 252-267, Table 1) discussed the empirical evidence as to whether the mentalising deficits in schizophrenia are specific or the consequence of general cognitive impairment. In both reviews it was concluded that the evidence speaks in favour of the notion that there is a specific theory of mind deficit in schizophrenia. As with many neurocognitive tests, theory of mind tasks probably measure several component processes at the same time. For example, tasks in which the comprehension of indirect speech is assessed may require not only mentalising abilities but also basic language comprehension and expressive language skills. Possibly, general cognitive abilities represent a necessary but not sufficient condition for adequate mentalising, which is known as the 'building block' view of social cognition (see Penn et al, 1997).

\section{Mentalising in schizophrenia: state or trait dependency}

In his cognitive model of the relationship between meta-representation and the signs and symptoms of schizophrenia, Frith assumed that in people with this disorder, the initial development of mentalising abilities is relatively normal and that these abilities become impaired as the illness develops (Frith, 1992). In the subsequent studies by him and his colleagues, it was predicted and found that patients who were in remission (i.e. symptom-free) were unimpaired compared with normal controls (e.g. Corcoran et al, 1995, 1997; Frith \& Corcoran, 1996; Pickup \& Frith, 2001). In contrast, our meta-analysis has shown that patients have significant impairment during remission, which is consistent with the findings of Herold et al (2002). These findings support the notion that mentalising is not just a consequence of the acute phase of the disorder but may be traitdependent. It cannot be excluded that the criteria for remission (e.g. partial or full remission) used by Herold et al (2002) and by Frith and colleagues are different. Other factors such as (prophylactic) treatment may also explain the divergent findings. However, more support for the trait argument comes from studies on mentalising in populations at elevated risk of developing a psychotic illness.

In general, people at genetic risk of schizophrenia show reduced performance on the more common types of theory of mind tasks (Wykes et al, 2001; Irani et al, 2006; Marjoram et al, 2006), but not on the 'eyes' test (Kelemen et al, 2004; Irani et al, 2006). In the study by Schiffman et al (2004), genetic high-risk children who would later develop schizophreniaspectrum disorders had lower scores on a role-taking task, which the authors considered assessed a facet of theory of mind. An association between theory of mind performance and subclinical schizotypal traits has also been found (Langdon \& Coltheart, 1999, 2004; Irani et al, 2006; Meyer \& Shean, 2006). Pickup (2006) showed that schizotypal traits analogous to positive symptoms of schizophrenia predicted poorer mentalising performance, whereas no association was found between poorer theory of mind and schizotypal traits analogous to the 'behavioural signs' of schizophrenia. Platek et al (2003) suggested that contagious yawning is part of a more general phenomenon known as mental state attribution. Consistent with this hypothesis, susceptibility to contagious yawning was positively related to performance on (other) mentalising tasks, and negatively related to schizotypal personality traits. Only in the study by Jahshan \& Sergi (2007) was there no difference between people with high schizotypy and those with low schizotypy regarding theory of mind performance. There is thus considerable evidence that mentalising impairment is a susceptibility indicator for schizophrenia and hence may be trait-dependent.

\section{Limitations}

The first limitation, to which we have already alluded, is that studies were excluded in which less common types of theory of mind tasks were used. Because there is no information on the psychometric properties of the many different tasks, this is somewhat arbitrary. In addition, the categorisation of task type is not supported by psychometric evidence. Second, the method of categorising symptom subgroups employed in this meta-analysis should be considered tentative. The main problem with our approach is that there is overlap between symptom clusters; for example, the subgrouping method used by Frith and colleagues is hierarchical, with the behavioural subgroup being the highest category. This means that patients in that subgroup could also report paranoid symptoms, but those in the paranoid subgroup could not report behavioural symptoms. As another example, participants categorised as paranoid in the study by Harrington et al (2005b) could also have formal thought disorder (which was indeed the case). However, in spite of this limitation, we believe that the results of the subgroup analyses in this meta-analysis are valuable. This is statistically supported by the homogeneity analyses, which show that the clustering of symptom subgroups did not result in more variation than would be expected from sampling error alone and that it is plausible that the studies within the subgroup analyses are comparable.

\section{Recommendations for future research}

The results and limitations of this metaanalysis lead to some recommendations for future research. First, research focusing on the mentalising process itself is necessary, addressing questions on what components it comprises and on how to operationalise them. As has already been pointed out by Harrington et al (2005a), it is also important to establish the psychometric properties of theory of mind tasks. Second, the finding that the deficit in theory of mind in schizophrenia is perhaps traitdependent rather than state-dependent implies that the deficit may also be present before illness onset. Therefore, there may be a role of mentalising impairment in the early detection and prediction of schizophrenia, requiring a longitudinal study examining theory of mind abilities in people at risk of developing schizophrenia. 
Third, the finding that theory of mind impairment may be trait-dependent also brings to mind a comparison with autismspectrum disorders. An impaired ability to understand mental states has been described as one of the core symptoms of such disorders (Yirmiya et al, 1998). However, although the risk of psychotic disorder is elevated in individuals with autism-spectrum disorder (Stahlberg et al, 2004), most of them will not develop a psychotic disorder. Future research should focus on what the commonalities and differences are with regard to theory of mind in these disorders. Abu-Akel \& Bailey (2000) for example suggested that there might be different forms of impairment of theory of mind. They argue that, unlike people with autism-spectrum disorders, people with schizophrenia do not lack an understanding that others have mental states; instead, they may overattribute knowledge to others or apply their knowledge of mental states in an incorrect or biased way. Thus, an interesting research topic would be a comparison of the mentalising abilities of groups of people with these two disorders.

Lastly, social impairment is one of the most disabling clinical features of schizophrenia and it is well known that it is often present before illness onset (e.g. Niemi et al, 2003). Since theory of mind impairment appears to be trait- rather than statedependent in schizophrenia, this deficit may have a role in the development of social impairment. However, evidence of a relationship between theory of mind performance and social functioning is lacking and should be an aim of future research.

\section{ACKNOWLEDGEMENTS}

This study was supported by a grant from ZorgOnderzoek Nederland/NWO-Medische Wetenschappen, project 2630.0001 .

\section{REFERENCES}

Abu-Akel, A. \& Bailey, A. L. (2000) The possibility of different forms of theory of mind impairment in psychiatric and developmental disorders. Psychological Medicine, 30, 735-738.

Blakemore, S. J., Sarfati, Y., Bazin, N., et al (2003) The detection of intentional contingencies in simple animations in patients with delusions of persecution. Psychological Medicine, 33, 1433-1441.

Brüne, M. (2003) Theory of mind and the role of $I Q$ in chronic disorganized schizophrenia. Schizophrenia Research, 60, 57-64.

Brüne, M. (2005a) 'Theory of mind' in schizophrenia: a review of the literature. Schizophrenia Bulletin, 31, 21-42.

MIRJAM SPRONG, MA, PATRICIA SCHOTHORST, MD, PhD, ELLEN VOS, MD, Department of Child and Adolescent Psychiatry, University Medical Centre Utrecht; JOOP HOX, PhD, Faculty of Social Sciences, Department of Methodology and Statistics, Utrecht University; HERMAN VAN ENGELAND, MD, PhD, Department of Child and Adolescent Psychiatry, University Medical Centre, The Netherlands

Correspondence: Ms M. Sprong, Department of Child and Adolescent Psychiatry, University Medical Centre, Heidelberglaan 100, HPA01.468, 3508 GA Utrecht, The Netherlands. Email: m.sprong-2@umcutrecht.nl

(First received 20 January 2007, final revision 21 February 2007, accepted 28 February 2007)

Brüne, M. (2005b) Emotion recognition, 'theory of mind', and social behavior in schizophrenia. Psychiatry Research, 133, 135-147.

Brüne, M. \& Bodenstein, L. (2005) Proverb comprehension reconsidered - 'theory of mind' and the pragmatic use of language in schizophrenia. Schizophrenia Research, 75, 233-239.

Brunet, E., Sarfati, Y., Hardy-Baylé, M. C., et al (2003a) Abnormalities of brain function during a nonverbal theory of mind task in schizophrenia. Neuropsychologia, 41, 1574-1582.

Brunet, E., Sarfati, Y. \& Hardy-Baylé, M. C. (2003b) Reasoning about physical causality and other's intentions in schizophrenia. Cognitive Neuropsychiatry, 8, 129-139.

Cohen, J. (1988) Statistical Power Analysis for the Behavioral Sciences. Erlbaum.

Corcoran, R. (2003) Inductive reasoning and the understanding of intention in schizophrenia. Cognitive Neuropsychiatry, 8, 223-235.

Corcoran, R. \& Frith, C. D. (2003) Autobiographical memory and theory of mind: evidence of a relationship in schizophrenia. Psychological Medicine, 33, 897-905.

\section{Corcoran, R., Mercer, G. \& Frith, C. D. (1995)} Schizophrenia, symptomatology and social inference: investigating 'theory of mind' in people with schizophrenia. Schizophrenia Research, 17, 5-13.

Corcoran, R., Cahill, C. \& Frith, C. D. (1997) The appreciation of visual jokes in people with schizophrenia: a study of 'mentalizing' ability. Schizophrenia Research, 24, $319-327$

Craig, J. S., Hatton, C., Craig, F. B., et al (2004) Persecutory beliefs, attributions and theory of mind comparison of patients with paranoid delusions, Asperger's syndrome and healthy controls. Schizophrenia Research, 69, 29-33.

Doody, G. A., Gotz, M., Johnstone, E. C., et al (1998) Theory of mind and psychoses. Psychological Medicine, 28, 397-405.

Frith, C. D. (1992) The Cognitive Neuropsychology of Schizophrenia. Psychology Press.

Frith, C. D. \& Corcoran, R. (1996) Exploring 'theory of mind' in people with schizophrenia. Psychological Medicine, 26, 521-530.

Harrington, L., Siegert, R. J. \& McClure, J. (2005a) Theory of mind in schizophrenia: a critical review. Cognitive Neuropsychiatry, 10, 249-286.

Harrington, L., Langdon, R., Siegert, R. J., et al (2005b) Schizophrenia, theory of mind, and persecutory delusions. Cognitive Neuropsychiatry, 10, 87-104.

Heinrichs, R. W. \& Zakzanis, K. K. (1998) Neurocognitive deficit in schizophrenia: a quantitative review of the evidence. Neuropsychology, 12, 426-445.
Herold, R., Tenyi, T., Lenard, K., et al (2002) Theory of mind deficit in people with schizophrenia during remission. Psychological Medicine, 32, I125-1129.

Irani, F., Platek, S. M., Panyavin, I. S., et al (2006) Self-face recognition and theory of mind in patients with schizophrenia and first-degree relatives. Schizophrenia Research, 88, 151-160.

Jahshan, C. S. \& Sergi, M. J. (2007) Theory of mind, neurocognition, and functional status in schizotypy. Schizophrenia Research, 89, 278-286.

Janssen, I., Krabbendam, L., Jolles, J., et al (2003) Alterations in theory of mind in patients with schizophrenia and non-psychotic relatives. Acta Psychiatrica Scandinavica, 108, II0-117.

Kelemen, O., Keri, S., Must, A., et al (2004) No evidence for impaired 'theory of mind' in unaffected first-degree relatives of schizophrenia patients. Acta Psychiatrica Scandinavica, II0, 146-149.

Kelemen, O., Erdelyi, R., Pataki, I., et al (2005)

Theory of mind and motion perception in schizophrenia. Neuropsychology, 19, 494-500

Kington, J. M., Jones, L. A., Watt, A. A., et al (2000) Impaired eye expression recognition in schizophrenia. Journal of Psychiatric Research, 34, 34I-347.

Langdon, R. \& Coltheart, M. (1999) Mentalising, schizotypy, and schizophrenia. Cognition, 7I, 43-7I.

Langdon, R. \& Coltheart, M. (200I) Mentalising, executive planning and disengagement in schizophrenia. Cognitive Neuropsychiatry, 6, 81-108.

Langdon, R. \& Coltheart, M. (2004) Recognition of metaphor and irony in young adults: the impact of schizotypal personality traits. Psychiatry Research, I25, 9-20.

Langdon, R., Michie, P. T., Ward, P. B., et al (1997)

Defective Self and/or Other mentalising in

schizophrenia: a cognitive neuropsychological approach. Cognitive Neuropsychiatry, 2, 167-193.

Langdon, R., Davies, M. \& Coltheart, M. (2002a) Understanding minds and understanding communicated meanings in schizophrenia. Mind and Language, I7, $68-104$

Langdon, R., Coltheart, M., Ward, P. B., et al (2002b) Disturbed communication in schizophrenia: the role of poor pragmatics and poor mind-reading. Psychological Medicine, 32, 1273-1284.

Langdon, R., Coltheart, M. \& Ward, P. B. (2006)

Empathetic perspective-taking is impaired in schizophrenia: evidence from a study of emotion attribution and theory of mind. Cognitive Neuropsychiatry, II, 133-155

Lipsey, M. W. \& Wilson, D. B. (200I) Practical MetaAnalysis. Sage.

Marjoram, D., Tansley, H., Miller, P., et al (2005a) A theory of mind investigation into the appreciation of visual jokes in schizophrenia. BMC Psychiatry, 5, 12 . 
Marjoram, D., Gardner, C., Burns, J., et al (2005b) Symptomatology and social inference: a theory of mind study of schizophrenia and psychotic affective disorder. Cognitive Neuropsychiatry, 10, 347-359.

Marjoram, D., Miller, P., Mclntosh, A. M., et al (2006) A neuropsychological investigation into 'Theory of Mind' and enhanced risk of schizophrenia. Psychiatry Research, 144, 29-37

Mazza, M., De Risio, A., Surian, L., et al (200I) Selective impairments of theory of mind in people with schizophrenia. Schizophrenia Research, 47, 299-308.

Mazza, M., De Risio, A., Tozzini, C., et al (2003) Machiavellianism and theory of mind in people affected by schizophrenia. Brain and Cognition, 5I, 262-269.

Meyer, J. \& Shean, G. (2006) Social-cognitive functioning and schizotypal characteristics. Journal of Psychology, 140, 199-207.

Niemi, L. T., Suvisaari, J. M., Tuulio-Henriksson, A. et al (2003) Childhood developmental abnormalities in schizophrenia: evidence from high-risk studies. Schizophrenia Research, 60, 239-258.

Penn, D. L., Corrigan, P. W., Bentall, R. P., et al (1997) Social cognition in schizophrenia. Psychological Bulletin, I2I, |14-132

Pickup, G. J. (2006) Theory of mind and its relation to schizotypy. Cognitive Neuropsychiatry, II, 177-192.

Pickup, G. J. \& Frith, C. D. (200I) Theory of mind impairments in schizophrenia: symptomatology, severity and specificity. Psychological Medicine, 3I, 207-220.

Platek, S. M., Critton, S. R., Myers, T. E., et al (2003) Contagious yawning: the role of self-awareness and mental state attribution. Brain Research and Cognitive Brain Research, 17, 223-227.
Randall, F., Corcoran, R., Day, J. C., et al (2003) Attention, theory of mind, and causal attributions in people with persecutory delusions: a preliminary investigation. Cognitive Neuropsychiatry, 8, 287-294.

Rudner, L. M., Glass, G. V., Evartt, D. L., et al (2002) Meta-Stat - A User's Guide to the Meta-Analysis of Research Studies. ERIC Clearinghouse on Assessment and Evaluation Department of Measurement, Statistics and Evaluation, University of Maryland (http: // www.edres.org/meta).

Russell, T. A., Rubia, K., Bullmore, E.T., et al (2000) Exploring the social brain in schizophrenia: left prefrontal underactivation during mental state attribution. American Journal of Psychiatry, 157, 2040-2042

Russell, T. A., Reynaud, E., Herba, C., et al (2006) Do you see what I see? Interpretations of intentional movement in schizophrenia. Schizophrenia Research, $8 \mathbf{I}$ IOI-III.

Sarfati, Y. \& Hardy-Baylé, M. C. (1999) How do people with schizophrenia explain the behaviour of others? A study of theory of mind and its relationship to thought and speech disorganization in schizophrenia. Psychological Medicine, 29, 613-620.

Sarfati, Y., Hardy-Baylé, M. C., Besche, C., et al (1997a) Attribution of intentions to others in people with schizophrenia: a non-verbal exploration with comic strips. Schizophrenia Research, 25, 199-209.

Sarfati, Y., Hardy-Baylé, M. C., Nadel, J., et al (1997b) Attribution of mental states to others by schizophrenic patients. Cognitive Neuropsychiatry, 2, I-17.

Sarfati, Y., Hardy-Baylé, M. C., Brunet, E., et al (1999) Investigating theory of mind in schizophrenia: influence of verbalization in disorganized and non- disorganized patients. Schizophrenia Research, 37 $183-190$

Sarfati, Y., Passerieux, C. \& Hardy-Baylé, M. (2000) Can verbalization remedy the theory of mind deficit in schizophrenia? Psychopathology, 33, 246-25I.

Schiffman, J., Lam, C. W., Jiwatram, T., et al (2004) Perspective-taking deficits in people with schizophrenia spectrum disorders: a prospective investigation Psychological Medicine, 34, 158I-1586.

Sperber, D. \& Wilson, D. (2002) Pragmatics, modularity and mind-reading. Mind and Language, 17 3-23.

Stahlberg, O., Soderstrom, H., Rastam, M., et al (2004) Bipolar disorder, schizophrenia, and other psychotic disorders in adults with childhood onset $A D$ $\mathrm{HD}$ and/or autism spectrum disorders. Journal of Neural Transmission, III, 891-902.

Wykes, T., Hamid, S. \& Wagstaff, K. (200I) Theory of mind and executive functions in the non-psychotic siblings of patients with schizophrenia. Schizophrenia Research, 49, 148.

Yirmiya, N., Erel, O., Shaked, M., et al (1998) Metaanalyses comparing theory of mind abilities of individuals with autism, individuals with mental retardation, and normally developing individuals. Psychological Bulletin, 124, 283-307.

Zalla, T., Bouchilloux, N., Labruyere, N., et al (2006) Impairment in event sequencing in disorganised and nondisorganised patients with schizophrenia. Brain Research Bulletin, 68, 195-202. 